\title{
Technology Transfer as a Function of Position in the Spectrum from Research through Development to Technical Services
}

Thomas J. Allen, Michael L. Tushman $\varepsilon$ Denis Lee

March, 1978

Working Paper No. 1005-78 replaces $918-77$ 
There are at least three general strategies which an R\&D organization can employ to keep abreast of relevant technological developments. First, to the extent that the organization is growing or enjoys a regular turnover of personnel, it can attempt to hire new employees who are acquainted with recent technological developments. In other words, it imports new technological know-how by hiring those who possess it (Allen and Cooney, 1974; Burns, 1973). Second, since some technological developments are well documented, it can invest in the means to provide its members with access to this documentation (Menze], 1966). Finally, it can encourage or arrange for direct formal or informal personal contact between its members and external sources of technological information. The last of these three general strategies is the focus of this research.

\section{PRIOR RESEARCH AND RESEARCH QUESTIONS}

\section{Extra Organizational Communication in Science and Technology}

Research investigating the relationship of extra-unit (i.e., laboratory or organization) communication and technical performance has yielded contrasting results. A very consistent inverse relation has been found between external communication and the performance of engineers and applied scientists in industrial organizations (Allen, 1964, 1977; Baker, et.al., 1967; Shilling \& Bernard, 1964). However, studies focusing on research scientists in universities as well as in industrial laboratories have demonstrated a very strong direct relation between performance and communication with colleagues outside the organization (Farris, 1972; Parker, Linwood, and Paisley, 1968; Tushman, 1978; Hagstrom, 1965).

Why should these differences exist? One explanation lies in the subtle but major distinction between science and technology (Price, 1965). Science can be said to be universal. Within a given specialty scientists are working toward the same ends and operating within a common social system (Kuhn, 1962; Crane, 1972). 
A scientists is, therefore, fully capable of understanding the nature of the problems and approaches employed by other scientists in his specialty anywhere in the world. The universal nature of the problems and the existence of shared language and methods permit effective communication across organizational and even national boundaries.

Technology, on the other hand, is not universal. Technology is highly localized in that problems are defined in terms of the interests, goals, and local culture of the organization in which they are being attacked. Similar technological problems may become defined in very dissimilar ways by organizations working on them since these organizations often have different objectives and value systems (Burns and Stalker, 1966; Allen, 1977).

A consequence of organizational differences is that technological problems are defined to fit the particular strengths, professional orientation, and objectives of the organization. Certain types of solutions, which may be perfectly acceptable in one organization, will simply not work when applied to the same problem in another organization. These organizational differences and priorities are not usually apparent to an outsider and as a consequence, make it very difficult for the external consultant to fully understand the nature of a locally defined technological problem. Both parties may think that the external consultant understands the problem, but this understanding is usually incomplete, and the proposed solutions or suggestions are not likely to fully match the locally defined solution space. As a result, the externally defined solutions perform less well, and we observe the resulting inverse relation between external consultation and technical performance.

The Technological Gatekeeper and Communication Outside the Organization

The major differences in the ease and efficiency of communicating scientific vs. technological information across organizational boundaries leave the problem of transferring technology between organizations largely unresolved. As keeping abreast of external technical developments is critical for R\&D organizations 
(technology-oriented systems), the more formal mechanisms of recruiting, transfer, and documentation may not be sufficient. It may be that more informal mechanisms evolve to effectively transfer technological information into the laboratory and thereby compliment the formal mechanisms.

To investigate this question, a number of researchers have studied communication patterns in R\&D settings. In the tradition of the social influence research (for example, Katz and Lazarsfeld, 1955; Coleman, Katz, and Menzel, 1966), high internal communicators, or communication stars, were identified and then compared with their less communicative colleagues. The key dimension on which comparison was made was the degree of technical communication outside the organization. The internal communication stars were found to have a significantly higher degree of informal contact with colleagues outside of their organization and to have a significantly higher readership of the professional scientific and engineering literature (A1len and Cohen, 1969; Allen, 1977; Whitley and Frost, 1973; Tushman, 1977; Frost and Whitley, 1971; Taylor and Utterback, 1975).

Those internal stars who also maintained a high degree of external communication were labelled technological gatekeepers (Allen and Cohen, 1969). These boundary-spanning individuals were not merely high communicators -- they were high technical performers, they were professionally oriented, they were overrepresented at lower levels of the organizational hierarchy, and finally, they were not formally recognized by the organization.

This review suggests alternative modes of transferring information across organizational boundaries; scientists pursuing more basic research can rely on direct contact or the scientific literature, while technologists can rely on technological gatekeepers to transfer information from external areas into the laboratory. Much of the literature in R\&D management has focused on development oriented work. If, however, the R\&D laboratory has a range of projects from 
basic research to very applied technical service work, then there may be alternative mechanisms for the transfer of technology into the laboratory. More specifically, this review suggests the following:

Hypothes is IA: For universal tasks (i.e., research) there will be a direct relationship between the mean level of extra-organizational communication and technical performance.

1B: Further for research projects, there will be an inverse relationship between the degree to which extra-organizational communication is skewed across project members and project performance (that is, the more evenly distributed the extraunit communication, the higher the performance of research projects).

Hypothesis 2A: More locally-oriented development or technical service projects will have an inverse relationship between extra-organizational communication and technical performance.

2B: Development and Technical Service tasks will have a direct relationship between the degree to which extra-organizational communication is positively skewed across project members and project performance (that is, the more a few key individuals do the bulk of the external communication, the higher the project's performance).

\section{RESEARCH SETTINGS AND METHODS}

This study was carried out at the R\&D facility of a large corporation in the United States. The R\&D facility is isolated from the rest of the corporation and employs 735 people. This study focused on all the professionals in the facility $(n=345)$. The laboratory was organized into seven divisional labs (or Groups). These Groups were organized into separate projects (or work areas). The projects were stable units over the course of the study; each respondent was a member of only one project. 
Technical Communication

To gather communication data, each professional was asked to specify those individuals with whom he had work-related oral communication on a given sampling day. These sociometric data were collected on a randomly chosen day each week for 15 weeks. The sampling of days was constrained to provide equal representation for each of the weekdays. Respondents were asked to report all oral work-related communications within and outside the laboratory (both to whom they talked and how many times they talked to that person during the day). They were not asked to report contacts which were strictly social, nor did they report written communications.

Each respondent was also asked to check the content category of each communication (for example, problem definiton or evaluation, idea generation, information location, and administrative matters). The first three of these categories will be aggregated as technical communication. During the 15 weeks, the overall response rate was 93 percent. Moreover, 68 percent of a11 the communications within the Taboratory were reported by both parties (see Weiss and Jacobson, 1960, for comparative data). The research procedures are similar to those used in other sociometric communication studies such as Allen and Cohen (1969), Whitley and Frost (1973), and Schwartz and Jacobson (1977).

The self-reported communication data were adjusted over the 15 weeks. Missing data (for example, that due to vacation, out-of-town trips, non-returns, etc.) were taken into account by normalizing the reported communications to an average frequency per ten sampling days. Project communication is, then, a normalized measure of the average absolute amount of technical communication per person per project over 10 weeks. While several communication domains were defined, this study focuses on the amount of communication between project members and professionals outside the org. ation (i.e., researchers in universities, those met at professional society cor rences; and technical consultants). 


\section{Project Task Type}

In R\&D settings, tasks can differ by 1) length of time required for feedback; 2) specific problem vs. general problem orientation; and 3) their generation of new knowledge in contrast to their use of existing knowledge (Rosenbloom and Wolek, 1970). With these attributes, the following task categories were developed with the laboratory's management to form a task dimension ranging from more universal (research) to more locally defined (technical service).

1. Basic Research: Work of a general nature intended to apply to a broad range of applications or to the development of new knowledge about an area.

2. General Research: Work involving basic knowledge for the solution of a particular problem. The creation and evaluation of new concepts or components but not development for operational use.

3. Development: The combination of existing feasible concepts, perhaps with new knowledge, to provide a distinctly new product or process. The application of known facts and theory to solve a particular problem through exploratory study, design and testing of new components or systems.

4. Technical Service: Cost/performance improvement to existing products, processes or systems. Recombination, modification and testing of systems using existing knowledge. Opening new markets for existing products.

Using these difinitions, respondents were asked to select the category which best characterized the objectives of their project and to indicate, on a 3-point scale, how completely the project's objectives were represented by the selected category. The twelve possible answers to this question were arranged and scored along a single numerical scale ranging from completely basic research to completely technical service.

As in Pelz and Andrews (1966), respondents were also asked to indicate, on a separate question, what percentage of their project's work fell into each of the four previously defined categories. A weighted average of the percentages was calculated for each respondent to yield a score comparable with the previous question. The scored responses to these two questions were averaged (SpearmanBrown reliability $=.91)$. 
Project measures were calculated by averaging the individual member's scores. To check on the appropriateness of pooling, a one-way ANOVA compared within project variance with between-project variance, while Bartlett's M-test tested for the homogeneity of intra-project variance. Following these two broad tests, individual $\mathrm{F}$-tests ensured that the variance within each project was not significantly greater than the pooled variance. Measures for 55 of the projects passed all three tests.

\section{Project Performance}

Since the laboratory's management could not develop objective performance measures which would be comparable across the laboratory, a subjective measure, similar to that used by Lawrence and Lorsch (1967) was employed. Each Group manager $(n=7)$ and the laboratory directors $(n=2)$ were individualiy interviewed. They were asked to evaluate the overall technical performance of all the projects with which they were technically familiar.

Each manager interviewed was asked to make their informed judgements based on their knowledge of and experience with the various projects. If they could not make an informed judgement for a particular project, they were asked not to rate the project. Criteria the managers considered (but were not limited to) included: schedule, budget, and cost performance; innovativeness; adaptablility; and the ability to cooperate with other parts of the organization. Each project was independently rated by an average of 4.7 managers on a seven-point scale (from very low to very high). As the intercorrelations of the nine judges were moderately correlated (Spearman-Brown reliability $=.81$ ), individual ratings were averaged to yield overall project performance scores.

\section{RESULTS}


Mean Frequency of Communication by Project Members.

The hypotheses suggest systematically different mechanisms for communicating with professional areas outside of the laboratory. Due to the more universal nature of research projects and the resulting ease and utility of extra-organizational communication, it is hypothesized that there will be a direct, positive, relationship between external professional communication and project performance. However, due to the difficulties of effectively communicating local problem parameters across organizational boundaries, an inverse, or negative relationship between external professional communication and project performance is hypothesized for both development and technical service projects.

Relating project performance to extra-organizational professional communication, Figure 1 indicates a fairly strong positive relation for research projects, but a negative or inverse relation for development projects. The relationship between professional communication and project performance for technical service projects is positive but not statistically significant (Table 1).

TABLE 1

Relationships Between Project Performance and Mean Frequency of Technical Communication Outside of the Organization by Project Member

\begin{tabular}{lllllll}
\hline type of project & $\begin{array}{l}\text { mean performance of } \\
\text { project teams in which } \\
\text { communication is: }\end{array}$ & \multicolumn{1}{l}{ low } & high & df & $p$ \\
\hline research & 4.25 & 5.09 & 2.33 & 11 & 0.02 \\
development & 4.74 & 4.23 & -1.75 & 20 & 0.05 \\
technical service & 4.67 & 4.87 & 0.58 & 18 & N.S. \\
\hline
\end{tabular}




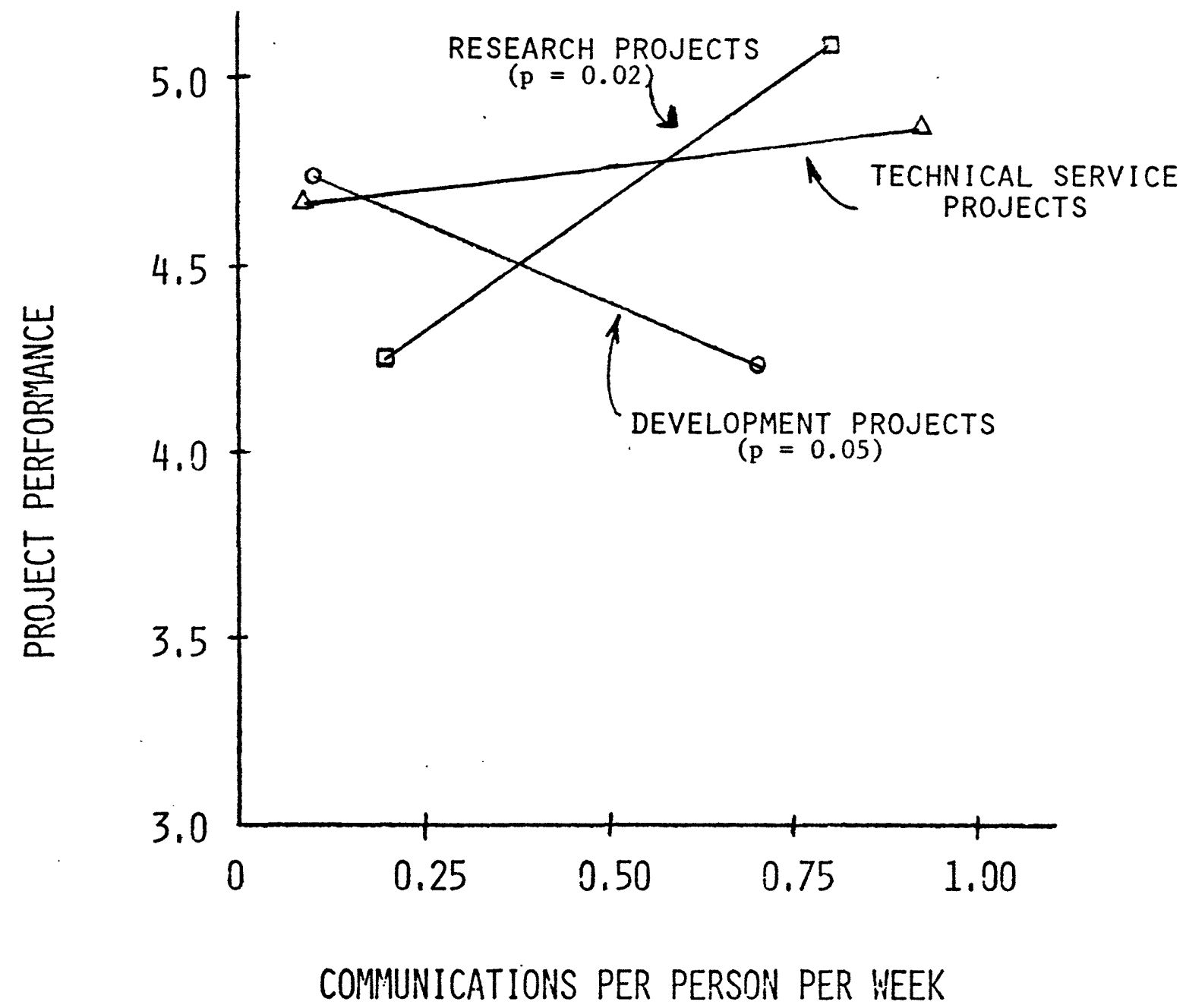

FIGURE 1. RELATIONSHIP BETHEEN PRDJECT PERFORIAAICE AND THE MEAN LEVEL OF TECHNICAL COMMUNICATION OUTSIDE THE ORGANIZATION. 
Another way of viewing these data is to correlate communication and performance separately for each of the three classes of project, and then using Analysis of Covariance, compare the slopes of the three regression lines.

The correlations follow a pattern similar to that found in the analysis of differences in means (Table II). The relationship in the case of development

\section{TABLE II}

Correlations Between Project Performance and Mean Frequency of

Technical Communication Outside of the Organization by Project Members

\begin{tabular}{lccc} 
type of project & $N$ & $r$ & $p$ \\
\hline research & 13 & 0.70 & 0.01 \\
development & 22 & -0.22 & 0.16 \\
technical service & 20 & 0.13 & 0.29
\end{tabular}

projects is no longer statistically significant, but is in the same direction observed previously. The differences among the three regressions is, however, significant (Table III). This interaction effect is even more marked when only research and development projects are considered. $\left(F_{1,31}=7.82 ; p<0.01\right)$.

As hypothesized, the data indicate different relationships between external technical communication and project performance for research and development projects. What is unexpected is the absence of any relationship for technical service projects. The actual mechanisms by which individuals, on the three types of project, best keep themselves technically informed remain to be explored. 
Analysis of Covariance for Project Performance and Mean Frequency of External Technical Communication by Project Members of Three Types of Project

\begin{tabular}{llllll}
\hline $\begin{array}{l}\text { variance in } \\
\text { performance }\end{array}$ & $\begin{array}{l}\text { sum of } \\
\text { squares }\end{array}$ & df & $\begin{array}{c}\text { estimate } \\
\text { of variance }\end{array}$ & $F$ & $P$ \\
\hline
\end{tabular}

unexplained by

type of project and communication 28.67 (assuming no interaction)

\section{explained by} interaction

error

$$
3.54
$$

25.13

\section{1}

$2 \quad 1.77$

$3.45 \quad 0.04$

Degree to Which Communication is Skewed Across Project Members.

The literature review suggested that difficulties of effectively communicating across organizational boundaries, would lead to the emergence of boundary spanning individuals (technological gatekeepers) who would handle the bulk of the external communication in both development and technical service areas. On the other hand, due to the relative ease and utility of direct external communication in the more universal research projects, the emergence of gatekeepers was hypothesized to be inversely associated with technical performance.

To test these role specialization ideas, the degree to which external communication was skewed across project members was computed for each project. To the extent that project members rely on gatekeepers for technical information then there should be substantial positive intra-project skew in external communication. If however, gatekeepers do not exist, then the skew in external communication will not be substantial; there will be a more even distribution of extraorganizational communication. 
The data in Figure 2 indicate that the variation in external communication across individual project members has markedly different relations with project performance. The degree to which members of research or technical service projects varied in their degree of external contact bore very little relation to the performance of the project. On the other hand, for development projects, the greater the positive skew in communicating. with external areas, the better their performance (Table IV).

TABLE IV

Relationship Between Project Performance and the Degree to Which Outside Technical Communication is Skewed Across Project Members

\begin{tabular}{|c|c|c|c|c|c|}
\hline \multirow{2}{*}{ type of project } & \multicolumn{2}{|c|}{$\begin{array}{l}\text { mean performance of } \\
\text { project teams in } \\
\text { which skewness is: }\end{array}$} & \multirow[t]{2}{*}{$t$} & \multirow[t]{2}{*}{$d f$} & \multirow[t]{2}{*}{$P$} \\
\hline & low & high & & & \\
\hline research & 4.79 & 4.66 & -0.26 & 10 & N.S. \\
\hline development & 4.16 & 4.73 & 1.79 & 18 & 0.05 \\
\hline technical service & 4.64 & 4.98 & 0.75 & 13 & N.S. \\
\hline
\end{tabular}

The set of results give some support to the idea of alternate modes of gathering external technical information. When research scientists uniformly increase their communication with the world outside their organization, they improve their chances of producing higher quality work. In contrast, when product development engineers decrease their average level of external communication but at the same time allow a few of their members to maintain or increase their external communication, their performance is enhanced. Thus, the amount of communication and the mechanism through which that communication is accomplished are related for these project types. Results for technical service projects are unclear; both 


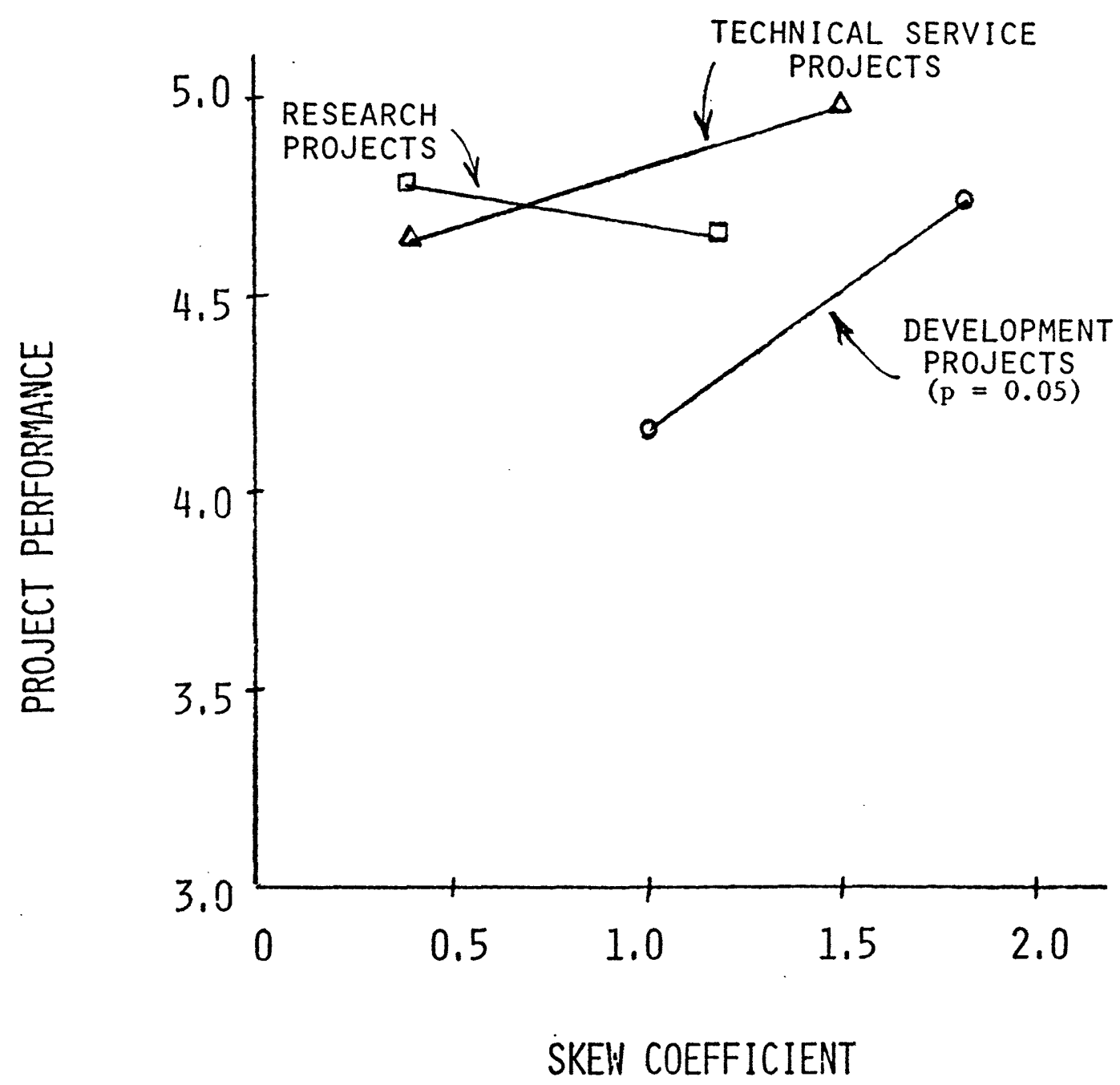

FIGURE 2. RELATIONSHIP BETHEEN PROJECT PERFORMANCE AND THE DEGREE TO :HICH THE DISTRIBUTION OF EXTERNAL TECHNICAL COMMUNICATION IS SKEWED ACROSS PROJECT MEMBERS. 
the amount and the variability of external communication were unrelated to project performance.

Analysis of Covariance for the three classes of project fails to show any significant difference among them, in the relation of communication skew to performance (Table V).

TABLE V

Analysis of Covariance for Project Performance and Degree to Which External Technical Communication is Skewed Across Project Team Members on Three Types of Project

\begin{tabular}{|c|c|c|c|c|c|}
\hline $\begin{array}{l}\text { variance in } \\
\text { performance }\end{array}$ & $\begin{array}{l}\text { sum of } \\
\text { squares }\end{array}$ & $d f$ & $\begin{array}{l}\text { estimate } \\
\text { of variance }\end{array}$ & $F$ & $p$ \\
\hline
\end{tabular}

unexplained by

type of project and communication (assuming no $26.70 \quad 43$

interaction)

explained by

interaction

$\begin{array}{lll}0.18 & 2 & 0.09\end{array}$

$0.14 \quad$ N.S.

$\begin{array}{llll}\text { error } & 26.52 & 41 & 0.65\end{array}$

DISCUSSION

Limitations on the Applicability of the Gatekeeper Concept

These results indicate that the contribution of the technological gatekeeper is contingent on the nature of the project's (or subunit's) task. These data along with Hagstrom's (1965) and Whitley and Frost's (1973) earlier work indicate that basic research scientists have little need for the specialized role of the gatekeeper. In science, individuals are less constrained by local circumstances 
and are able to communicate effectively with colleagues who share their research interests, regardless of where those colleagues might be.

The gatekeeper seems to be an offspring of technological needs and organizational conditions. Because technological problems are defined in local terms, reflecting the firm's interests and strategy, as well as the value system of the organization, most technologists have difficulty in communicating effectively with outsiders about those problems. Fortunately, however, there of ten appear a few individuals who maintain consistent ongoing contact outside their organizations, who understand the way in which outsiders differ in perspective from their organizational colleagues, and who are able to translate between the two systems. The gatekeeper is able to understand external technological developments and to translate these into terms that can be understood by and are relevant to his organizational colleagues. The gatekeeper, then, performs an extremely important role in RED settings; he is the principal channel for effectively transferring technology into the organization. In product development settings, gatekeepers are an informal phenomenon and operate at the lowest levels of the organization (first level supervisor and below).

There is some indication that the gatekeeper role is of greater importance when the technology is somewhat sophisticated (Spital \& Allen, 1976). The results here are not yet completely clear, but among the technical service projects, there is no relation between project performance and either the mean level of external communication nor the skew among individuals in external communication. It may be that for technical service projects, the administrative hierarchy assumes more of the responsibility for external communication. This is similar to the situations reported by Frost and Whitley (1971) where in a laboratory providing consulting services in metallurgy, they found that technical supervisors provided the laboratory's principal connection to the external information world. The 
16.

informal gatekeeper role, independent of the hierarchy, was less important in that laboratory. Similarly, the fact that Walsh and Baker (1972) did not find evidence of the informal gatekeeper role may be because the formal hierarchy assumed the responsibility for external communication. In both these studies the tasks were technical service in nature.

In technical service projects, the idea that the gatekeeper role may shift to the formal hierarchy, rather than being an informal phenomenon, stems from the fact that technologies employed in these projects are more established, less dynamic, and even more closely coupled to organizational considerations than are technologies used in product or process development. Since the technologies involved in technical service work are less complex and more easily dealt with and understood by the management of the organization, the formal organization, through its hierarchy, provides the majority of information required by personnel in technical service areas (Carlson, 1964; Pettigrew, 1973; Baldridge and Burnham, 1975).

Mode of Technology Transfer as a Function of the Nature of the Unit's Work

These results along with extant organizational literature suggest that consequences of formal organizations -- the control of reward systems and careers, the development of system boundaries -- create barriers to effective communication with external sources of information. Gatekeepers evolve to fulfill a need with which the formal organization is incapable of dealing. However, when the bureaucratic boundary is weak or absent, as in the case of research scientists, there is little need for such a boundary spanning role. For scientists working on universally defined tasks, the communication impedance is not substantial so that direct extra-organizational communication is an effective information medi ium. 
On the other hand, for more locally defined tasks, formal organizational boundaries are a serious impediment to effective communication with external areas. When technology is stable, formal mechanisms can be employed by the organization to bring technology to its users. High levels of the organization gather information and make technical decisions which are, in turn, diffused through the organization's formal hierarchy. Thus, the formal organization is able to handle situations in which technologies are well defined and stable, or when an innovation is already well-defined by the innovator or innovating organization.'

It is when there exists a well-defined organizational boundary and a dynamic technology that the technological gatekeeper is most important. The well-defined boundary with its attendant communication impedance requires some boundary spanning mechanism. The dynamic technology implies a need for someone who is intimately conversant with it to play the role of introducing new technology to the organization. Of course, to be intimately conversant with a dynamic technology, one must almost necessarily be contributing to it in a direct way. Such direct technological contributors are seldom found in higher levels of the organization. Therefore, it must be someone who is at or near the bottom of the organization who links their area to external technological changes. In other words, the organizational hierarchy is by-passed by informal relations developed by the gatekeeper with colleagues within and outside the organization. This informal, two-step, process is an important way in which a dynamic technology can be continuously drawn into an organization. It is, however, an avenue only necessary when the conditions of a locally defined

$1_{1}$ is in this context that several investigators have discovered an "opinion leader" role to be important (Katz, et.al., 1963; Carlson, 1964). Opinion leaders, in these studies, unlike gatekeepers, tended to be managers. They also tended to deal with more stable technology. This is an important distinction. When the technology is stable, the managerial hierarchy, through its "opinion leaders" can keep the organization informed. When the technology is dynamic, the gatekeeper, himself a contributor to the technology, best informs the organization. 
task (with its attendant communication boundary) and a dynamic technology co-exist.

\section{CONCLUSION}

In order to be innovative over a period of time, R\&D organizations must be continuously informed of external scientific and technological developments (Myers \& Marquis, 1969; Allen, 1977; Mansfield and Wagner, 1975). This research, along with existing research, indicates that if the laboratory is made up of subunits conducting work ranging on a research-development-technical service continuum, there will be several modes of transferring information from external areas into the different subunits. The specific mode of information transfer is contingent on the nature of the subunit's work.

More specifically, the combination of organizational constraints to communicate with external areas and the nature and demands of technology lead to the following alternative modes of information transfer; research projects rely on widespread direct contact with external professional areas; development projects rely on technological gatekeepers who are conversant with developments in relevant technologies and who diffuse this information through informal communication within the laboratory; while technical service projects seem to rely on the formal hierarchy to both gather information and formally disseminate it through the subunit. In short, the level in the hierarchy where information enters the laboratory, the existence of special boundary roles, and the nature of the diffusion process within the laboratory are contingent on the rate of change of the technology and the degree to which the work is locally defined or more universal in nature (Figure 3 ).

The concept of technological gatekeeper is, therefore, important only within limited circumstances. When a subunit (or laboratory) is conducting basic research, gatekeepers are not critical since the organization itself does not 
Direct external contact; Boundary Spanning Roles; mediated by hierINFORMAL DIFFUSION INFORMAL DIFFUSION ARCHY; FORMAL DIFFUSION

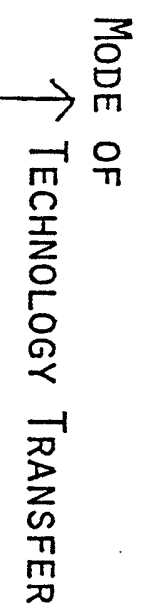

实兽

$\vec{s}-1$

皮

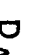

중

员

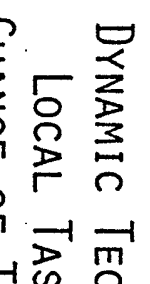

กิ

죠

(

a

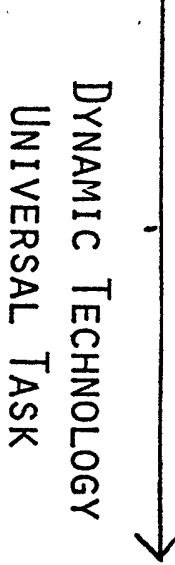

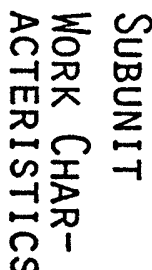

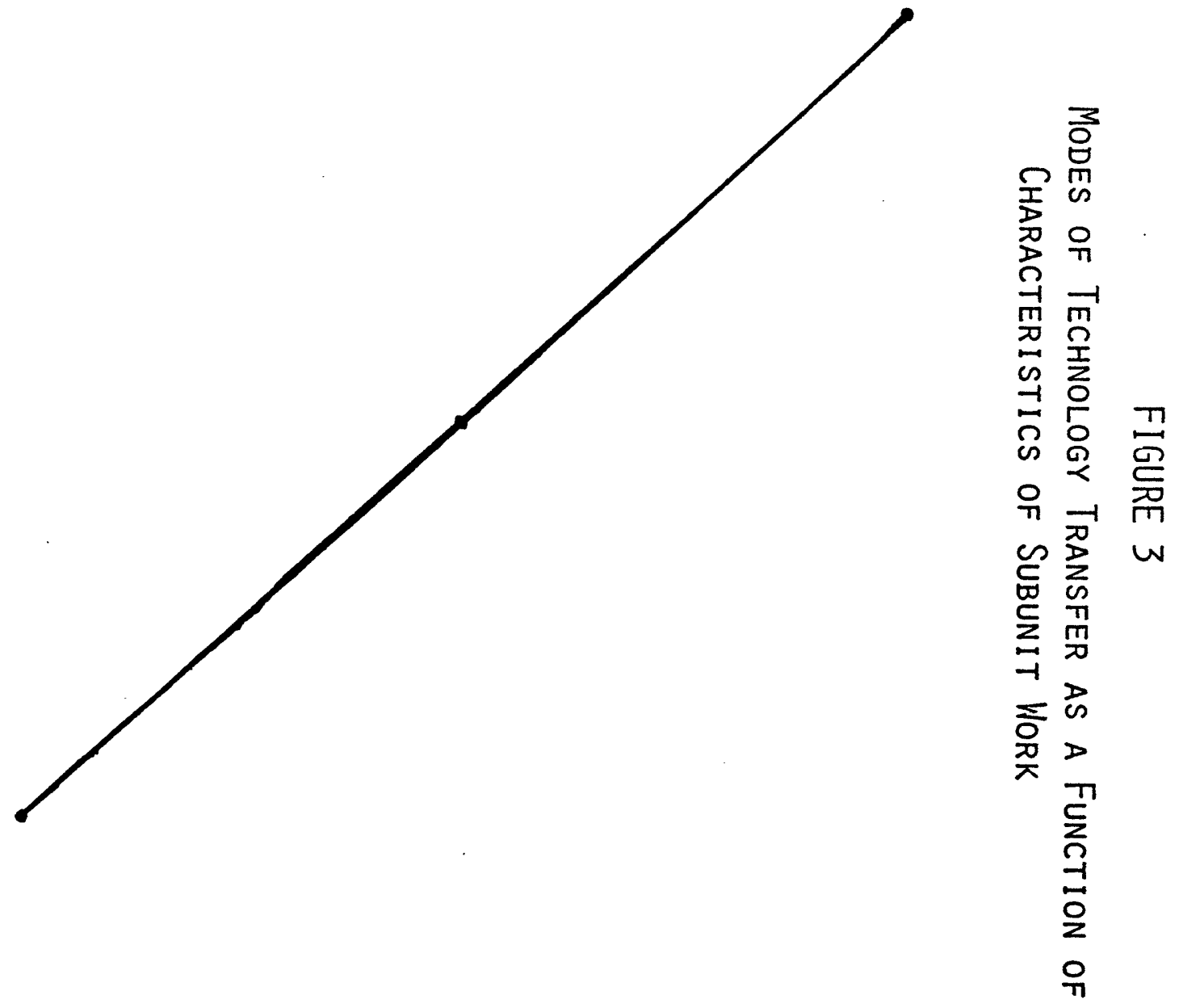


impede communication with the outside world. At the other end of the RED spectrum, if a subunit is concerned with the application of well-established technologies to well-specified situations, there is little need for gatekeepers since the organization is capable of structuring itself to provide the technical information needed by its members. It is only when the technologies become more complex, in development projects, that the need arises for gatekeepers. When the organization (or subunit) is concerned with innovation and is itself contributing to technological advancement, the gatekeeper provides the most effective link between the organization's efforts and those pursued elsewhere.

In conclusion, these results are consistent with other research which focuses on communication in RED (Allen, 1977; Tushman, 1977, 1978; Myers and Marquis, 1969; Whitley and Frost, 1973). This research tradition indicates that communication is an important process in RED settings, that communication patterns can be managed, and that communication patterns should be managed so that they best fit the information needs of the subunit's work (Tushman and Nadler, 1978). 


\section{REFERENCES}

Allen, T.J. The Use of Information Channels in RED Proposal Preparation. MIT Sloan School of Management, Working Paper, 1964.

Allen, T.J. Managing the Flow of Technology. Cambridge: MIT Press, 1977.

Allen, T.J. and Cohen, S. Information flow in RED laboratories. Administrative Science Quarterly, 14 (1969), 12-19.

Allen, T.J. and Cooney, S. Institutional roles in technology transfer. RED Management, 4 (1973), 41-51.

Baker, N., Siegmann, J., and Rubenstein, A. Effects of perceived means and needs on the generation of ideas in RED projects. IEEE Transactions on Engineering Management, 14 (1967), 156-163.

Baldridge, $V$. and Burnham, R. Organizational innovation: Individual, organizational, and environmental impacts. Administrative Science Quarterly, 20 (1975), 165-176.

Burns, T. Models, images and myths, in Gruber, W. and D. Marquis, Factors in the Transfer of Technology, Cambridge, MIT Press, 1969.

Carlson, R.C. Adoption of Educational Innovations, Eugene Oregon: Center for Advanced Study of Educational Administration.

Coleman, J., Katz, D., and Menzel, 1. Diffusion of Innovation. New York: Free Press, 1966.

Crane, D. Invisible Colleges. Chicago: University of Chicago Press, 1972.

Farris, G. The effect of individual roles on performance in innovative groups. R\&D Management, 3 (1972), 23-28.

Frost, R. and Whitley, R. Communication patterns in a research laboratory. RED Management, I (1971), 71-79.

Hagstrom, W. The Scientific Community. New York: Basic Books, 1965.

Katz, D. and Lazarfeld, P. Personal Influence. New York: Free Press of Glencoe, 1955.

Kuhn, T. The Structure of Scientific Revolutions. Chicago: University of Chicago Press, 1962.

Lawrence, P. and Lorsch, J. Organizations and Environment. Cambridge: Harvard University Press, 1967.

Mansfield, E. and Wagner, S. Organizational and strategic factors associated with probabilities of success in industrial research. Journal of Business, Winter, 1975, 179-198. 
Menzel, H. Information needs and uses in science and technology. In C. Cuadra (ed.), Annual Review of Information Science and Technology, New York:

Wiley \& Sons, 1966.

Myers, S. and Marquis, D. Successful Industrial Innovation. Washington, D.C.: National Science Foundation, 1969.

Parker, E., Linwood, D., Paisley, W. Communication and Research Productivity in an Interdisciplinary Behavioral Research Area. Stanford: Institute for Communication Research, 1968.

Pelz, D. and Andrews, F. Scientists in Organizations. New York: Wiley Co., 1966.

Pettigrew, A. The Politics of Organizational Decision Making. London: Tavistock Press, 1973.

Price, D. Is technology historically independent of science? A study in statistical historiography. Technology and Culture, 6 (1965), 553-568.

Rosenbloom, R. and Wolek, F. Technology and Information Transfer. Boston: Harvard Business School, 1970.

Schwartz, D. and Jacobson, W. Organizational communication network analysis: The liaison communication role. Organizational Behavior and Human Performance, $18,1977,158-174$.

Spital, F. and Allen T.J. Technology Transfer Under Varying Rates of Knowledge Generation, Sloan School of Management Working Paper No. 902-77.

Taylor, R. and Utterback, J. A longitudinal study of communication in research. IEEE Transactions on Engineering Management, EM 22 (1975), 80-87.

Tushman, M. Communication across organizational boundaries: Special boundary roles in the innovation process. Administrative Science Quarterly, forthcoming, 1977.

Tushman, M. Technical communication in research and development laboratories: Impact of project work characteristics. Academy of Management Journal, forthcoming, 1978.

Tushman, M. and Nadler, D. Communication and technical roles in RED laboratories: An information processing approach. Management Science, forthcoming, 1978.

Walsh, V. and Baker, A. Project management and communication patterns in industrial research. RED Management, 2 (1972), 103-109.

Weiss, R, and Jacobson, E. Structure of complex organizations. In: Mereno (ed.), Sociometry Reader. New York: Free Press, 1960, pp. 522-533.

Whitley, R. and Frost, P. Task type and information transfer in a government research laboratory. Human Relations, 25, (1973), 537-550. 